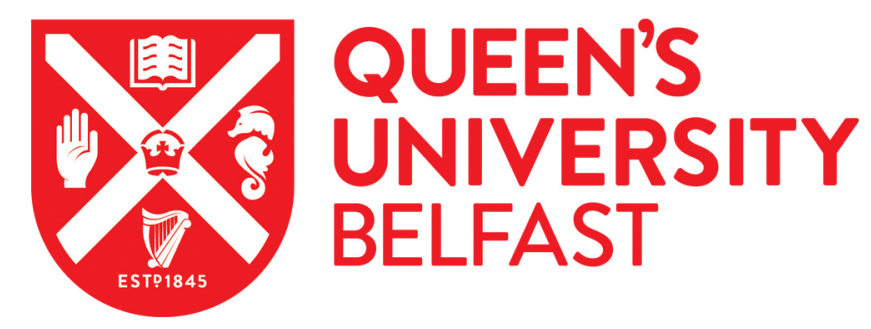

\title{
A High-Efficiency GaN Doherty Power Amplifier with Blended Class- EF Mode and Load-Pull Technique
}

Barakat, A., Thian, M., \& Fusco, V. (2017). A High-Efficiency GaN Doherty Power Amplifier with Blended ClassEF Mode and Load-Pull Technique. IEEE Transactions on Circuits and Systems II: Express Briefs.

https://doi.org/10.1109/TCSII.2017.2677745

Published in:

IEEE Transactions on Circuits and Systems II: Express Briefs

Document Version:

Peer reviewed version

Queen's University Belfast - Research Portal:

Link to publication record in Queen's University Belfast Research Portal

\begin{abstract}
Publisher rights
(C) 2017 IEEE.

Personal use of this material is permitted. Permission from IEEE must be obtained for all other users, including reprinting/ republishing this material for advertising or promotional purposes, creating new collective works for resale or redistribution to servers or lists, or reuse of any copyrighted components of this work in other works.")
\end{abstract}

\section{General rights}

Copyright for the publications made accessible via the Queen's University Belfast Research Portal is retained by the author(s) and / or other copyright owners and it is a condition of accessing these publications that users recognise and abide by the legal requirements associated with these rights.

Take down policy

The Research Portal is Queen's institutional repository that provides access to Queen's research output. Every effort has been made to ensure that content in the Research Portal does not infringe any person's rights, or applicable UK laws. If you discover content in the Research Portal that you believe breaches copyright or violates any law, please contact openaccess@qub.ac.uk. 


\title{
A High-Efficiency GaN Doherty Power Amplifier With Blended Class-EF Mode and Load-Pull Technique
}

\author{
Ayman Barakat, Student Member, IEEE, Mury Thian, and Vincent Fusco, Fellow, IEEE
}

\begin{abstract}
This paper presents a new Doherty power amplifier (DPA) configuration that employs high-efficiency switched-mode Class EF as its Main and Auxiliary cells. A blended approach is proposed to design the load network of the PA cells, in which the fundamental-frequency load impedance is obtained through loadpull analysis whereas the harmonic load impedances are set according to the Class-EF requirements. Realized using GaN HEMTs, the DPA prototype exhibits a drain efficiency (DE) of $81 \%$ at $45-\mathrm{dBm}$ peak power and $68 \%$ at $6-\mathrm{dB}$ back-off power, i.e. when excited using a $2.4 \mathrm{GHz}$ continuous-wave signal. The proposed DPA has a 3-dB bandwidth of nearly $300 \mathrm{MHz}$ within which the DE can be maintained above $68.5 \%$. Using 16-QAM signal with 5-MHz bandwidth and 6-dB peak-to-average power ratio, the DPA shows a DE of $69.7 \%$ and an ACLR 1 of $-26.6 \mathrm{dBc}$ at an average output power of $39.2 \mathrm{dBm}$.
\end{abstract}

Index Terms-Class-EF, Doherty, GaN HEMT, load pull, power amplifier, transmission line.

\section{INTRODUCTION}

$I^{\mathrm{N}}$ N THE classical Doherty power amplifier (DPA), the Main and Auxiliary cells are typically biased in Class AB and C modes, respectively, where the gate bias voltage of the Auxiliary cell is set below that of the Main cell in order to turn on the Auxiliary cell at 6-dB back-off power (BOP). Switchedmode Class-E DPAs and harmonically tuned DPAs wherein Class $\mathrm{F} \mathrm{F}^{-1}$ or $\mathrm{J}$ is employed as the Main and/or Auxiliary cells, have been shown to exhibit higher drain efficiencies compared to the traditional DPAs, [1]-[8].

The Class-EF PA introduced in [9]-[10] takes advantage of soft-switching operation offered by the Class $E$ and low peak switch voltage of the Class $F$ i.e. $2 \times V_{\mathrm{DC}}$. However, when operated at high frequency to deliver high output power, the theoretical value of the capacitance shunting the ideal switch in the Class-EF topology is typically lower than the actual transistor's equivalent output capacitance. To address this problem, the so-called Fifth-Harmonic-Peaking (FHP) Class-EF PA was proposed in [11]. This new PA variant specifically satisfies the Class-EF load-impedance requirements at fundamental frequency $\left(f_{0}\right)$, all even harmonics, and the first two odd harmonics, i.e. $3 f_{0}$ and $5 f_{0}$. In addition, the FHP ClassEF PA load network provides a means for simultaneous impedance matching to a typical $50-\Omega$ load resistance, thus dispensing the need for an additional output matching circuit

This work was supported by the Marie Curie European Industrial Doctorate (EID) programme under the ARTISAN project (grant no. 316426).

Ayman Barakat, Mury Thian and Vincent Fusco are with the Queen's University of Belfast, Queen's Road, Queen’s Island, Belfast, BT3 9DT, United Kingdom (email: abarakat02; m.thian; v.fusco@qub.ac.uk).

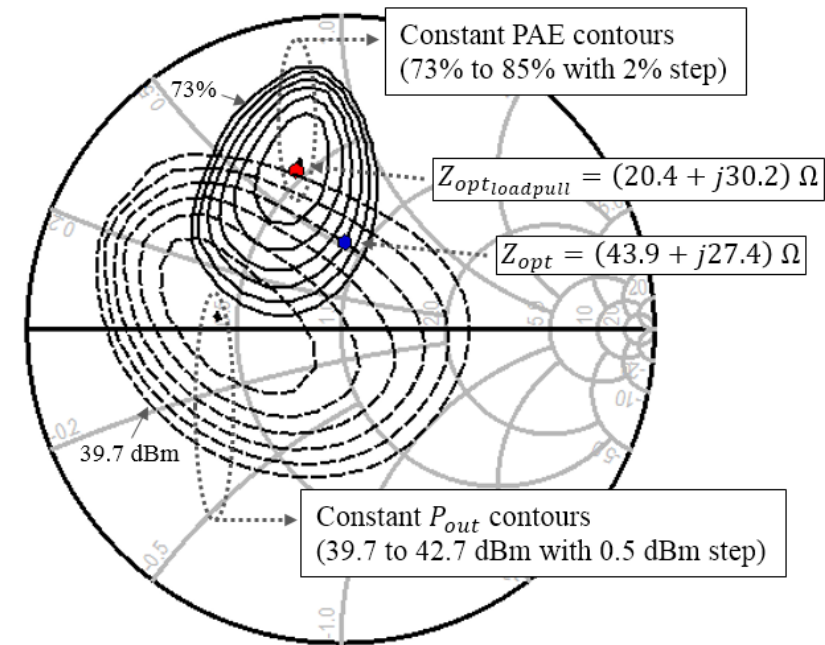

Fig. 1. Constant PAE and output power contours resulted from the load-pull simulation at $2.4 \mathrm{GHz}\left(P_{\text {in }}=29 \mathrm{dBm}, V_{D D}=28 \mathrm{~V}\right.$, and $\left.V_{G G}=-2.7 \mathrm{~V}\right)$.

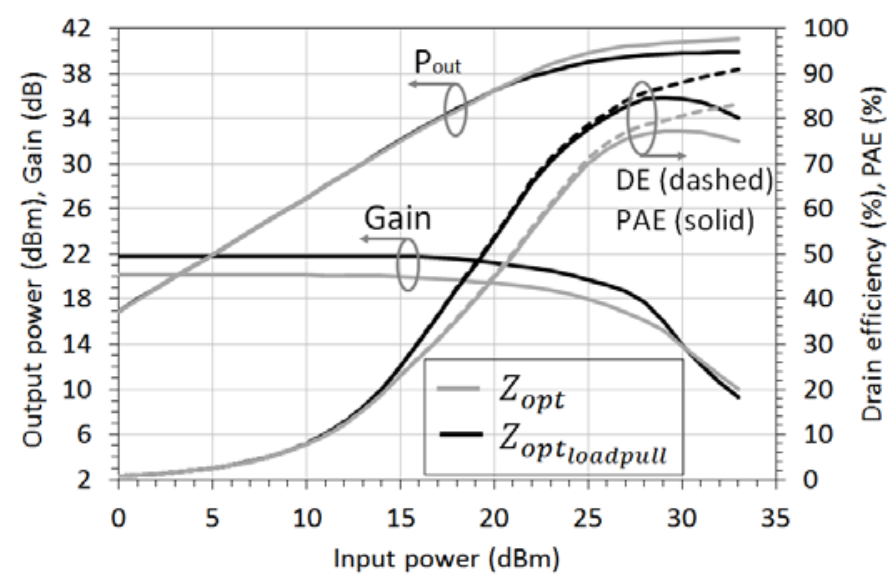

Fig. 2. Simulated PA performance at $2.4 \mathrm{GHz}$ for $Z_{\text {opt }}=(43.9+j 27.4) \Omega$ and $Z_{\text {opt } \text { loadpull }}=(20.4+j 30.2) \Omega$.

which would otherwise increase the overall loss.

The optimum fundamental-frequency load-impedance of Class EF $\left(Z_{\text {opt }}\right)$ is derived using Fourier analysis by treating the active device as an ideal switch [9], but neglecting the presence of bond-wire inductances and package parasitics in the actual transistors. Because of this, the theoretical $Z_{\text {opt }}$ will not provide best efficiency, and consequently, the load network's component values need to be tuned heavily in a practical design, hence increasing simulation time. In order to bridge the gap between the theory and practice, we propose a blended Class-EF mode and load-pull technique. Here the optimum fundamental-frequency load-impedance is obtained through load-pull simulations, whereas the load impedances presented to the output node of the transistor (i.e. drain) at harmonic frequencies will follow those in the Class EF. This load-pull 
FHP Class-EF PA will then be employed as the Main and Auxiliary cells of the DPA.

The paper is organized as follows. Section II will present the design and implementation of the load-pull FHP Class-EF PA cell. Section III will explain how the PA cell treated in Section II is incorporated in the proposed DPA configuration, and describe the procedure to calculate the output combiner's transmission-line parameters, the DPA realization and the measurement results. Conclusions will be provided at the end.

\section{LOAD-PULL FHP CLASS-EF POWER AMPLIFIER CELL: THEORY, DESIGN, AND IMPLEMENTATION}

To obtain the optimum fundamental-frequency load impedance which gives best power added efficiency (PAE) $\left(Z_{\text {opt }}\right.$ loadpull $)$, a load-pull simulation was performed on a Cree's 10-W CGH40010F GaN HEMT device. Here the $2^{\text {nd }}$ and $4^{\text {th }}$ harmonic load impedances were set to zero whereas the $3^{\text {rd }}$ and $5^{\text {th }}$ harmonic load impedances were set to a large value (in this case, $50 \mathrm{k} \Omega$ ), i.e. similar to that in the Class-EF mode. The gate and drain bias voltages were set to $V_{\mathrm{GG}}=-2.7 \mathrm{~V}$ and $V_{\mathrm{DD}}=28 \mathrm{~V}$. This arrangement resulted in $Z_{\text {opt }}$ loadpull $=$ $(20.4+j 30.2) \Omega$ at the required operating frequency $f_{0}=2.4$ GHz. Fig. 1 shows the locus of this impedance on the Smith chart with respect to the constant output power and PAE contours generated from the simulation. For comparison, the theoretical Class-EF's optimum fundamental-frequency loadimpedance $\left(Z_{\text {opt }}\right)$ is also plotted in Fig. 1. For a given dead time $\tau_{D}=48.5^{\circ}, V_{\mathrm{DD}}=28 \mathrm{~V}$, and output power $P_{\text {out }}=10 \mathrm{~W}$, $Z_{\text {opt }}$ is $(43.9+j 27.4) \Omega$, calculated using (1).

$$
Z_{\text {opt }}=\frac{2\left(1+\cos \tau_{D}\right)^{2}}{\pi^{2}} \frac{V_{D D}^{2}}{P_{\text {out }}}\left\{1+j \frac{\tau_{D}-0.5 \sin \left(2 \tau_{D}\right)}{\sin ^{2} \tau_{D}}\right\}
$$

Fig. 2 shows the simulated PA performance for $Z_{\text {opt }}$ and

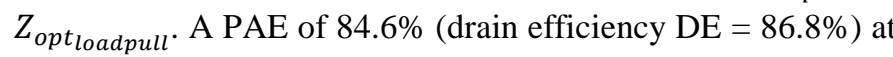
$39.7 \mathrm{dBm}$ output power and $16.1 \mathrm{~dB}$ gain was achieved for $Z_{\text {opt }}$ loadpull, showing a $7.4 \%$ improvement in PAE and a 2.2 $\mathrm{dB}$ improvement in the transducer gain (i.e. from 13.9 to 16.1 $\mathrm{dB}$ ) compared to the case of $Z_{\text {opt }}$. The next challenging step is to design the PA's load network that presents $Z_{\text {opt }}$ loadpull at $f_{0}$, a short circuit at $2 f_{0}$ and $4 f_{0}$, and an open circuit at $3 f_{0}$ and $5 f_{0}$. This can be accomplished by using the FHP Class-EF PA topology, Fig. 3. Note that $C_{\mathrm{B}}$ is a dc blocking capacitance. To find the electrical lengths and characteristic impedances of the idealized transmission lines $\mathrm{TL}_{1}-\mathrm{TL}_{8}$ shown in Fig. 3, we have followed the same circuit design methodology for the FHP Class-EF PA reported in [11].

Subsequently, the electrical parameters of these transmission lines were converted to the corresponding microstrip widths $(W)$ and lengths $(L)$, which were then optimized in the simulations to provide best efficiency. Both theoretical and optimized circuit component values are given in Table I. The complete circuit schematic of the load-pull FHP Class-EF PA is depicted in Fig. 4, and the simulated PA performance is shown in Fig. 5 where a maximum $\mathrm{PAE}$ of $81.3 \%(\mathrm{DE}=$ $84.8 \%$ ) was achieved at $41.4-\mathrm{dBm}$ output power and 13.8-dB

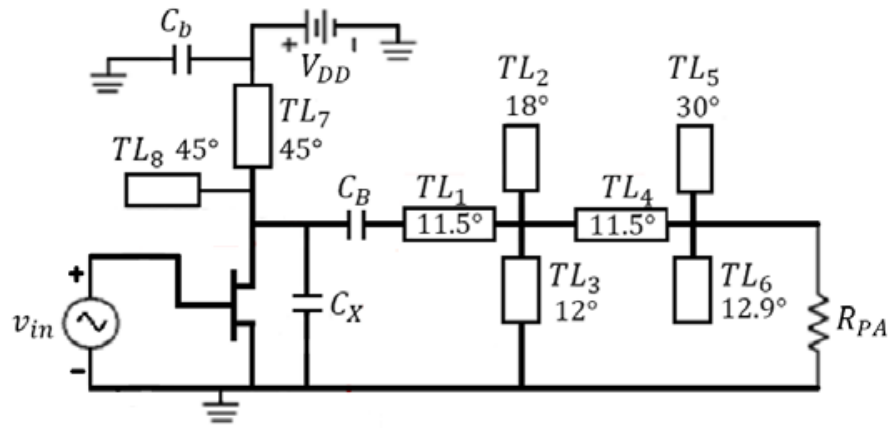

Fig. 3. Circuit schematic of the load-pull FHP Class-EF PA [11].

TABLE I

TRANSMISSION-LINE PARAMETER VALUES OF THE 2.4-GHz 28-V 10-W LOADPULL FHP CLASS-EF PA

\begin{tabular}{ccc}
\hline \hline Parameter & $\begin{array}{c}\text { Theoretical Value } \\
\text { (in mm) }\end{array}$ & $\begin{array}{c}\text { Optimized Value } \\
\text { (in mm) }\end{array}$ \\
\hline $\boldsymbol{W}_{\mathbf{1}}=\boldsymbol{W}_{\mathbf{4}}$ & 1.56 & 1.56 \\
\hline $\boldsymbol{L}_{\mathbf{1}}=\boldsymbol{L}_{\mathbf{4}}$ & 2.28 & 2.28 \\
\hline $\boldsymbol{W}_{\mathbf{2}}=\boldsymbol{W}_{\mathbf{3}}$ & 0.38 & 0.38 \\
\hline $\boldsymbol{L}_{\mathbf{2}}$ & 3.76 & 3.86 \\
\hline $\boldsymbol{L}_{\mathbf{3}}$ & 2.51 & 2.31 \\
\hline $\boldsymbol{W}_{\mathbf{5}}=\boldsymbol{W}_{\mathbf{6}}$ & 0.73 & 2.00 \\
\hline $\boldsymbol{L}_{\mathbf{5}}$ & 6.12 & 6.22 \\
\hline $\boldsymbol{L}_{\mathbf{6}}$ & 2.62 & 2.52 \\
\hline $\boldsymbol{W}_{\mathbf{7}}=\boldsymbol{W}_{\mathbf{8}}$ & 0.46 & 0.46 \\
\hline $\boldsymbol{L}_{\mathbf{7}}$ & 9.34 & 8.24 \\
\hline $\boldsymbol{L}_{\mathbf{8}}$ & 9.34 & 9.60 \\
\hline \hline
\end{tabular}

this simulation result and that presented in Fig. 2 wherein the PAE is slightly higher (i.e. 84.6\%) and output power is lower (i.e. $39.7 \mathrm{dBm}$ ). This is chiefly because the circuit used to generate the result presented in Fig. 2 employs an equationbased component, the so-called "S1P_Eqn", to set different load impedances at the fundamental and harmonic frequencies, whereas the result presented in Fig. 5 was produced using the transmission-line load-network arrangement shown in Fig. 3.

To verify the aforementioned design concepts and simulation results, a PA prototype was constructed on a 0.508 mm thick Rogers RO4003C substrate with a dielectric constant of 3.55 and a loss tangent of 0.0027 (Fig. 6). The CGH40010F GaN HEMT was biased with $V_{\mathrm{GG}}=-2.5 \mathrm{~V}$, and the PA was excited using a continuous wave (CW) signal at $2.4 \mathrm{GHz}$. Measured output power, gain, DE, and PAE were plotted in Fig. 7. A maximum $\mathrm{DE}$ of $84.4 \%(\mathrm{PAE}=80.8 \%)$ was achieved at 40.4-dBm output power and 13.8-dB gain. Fig. 8 shows the PA performance across a frequency range from 2 to $2.8 \mathrm{GHz}$ within which the DE is higher than $61 \%$.

\section{ClAss-EF DOHERTY POWER AMPLIFIER: THEORY, DESIGN, AND IMPLEMENTATION}

Shown in Fig. 9 is the block diagram of the proposed Doherty PA in which the load-pull FHP Class-EF PA described in Section II is employed as the Main and Auxiliary PA cells. Compared with the classical Class-B DPA [12], the new Class-EF DPA offers higher instantaneous drain efficiencies at both peak power and BOP levels, Fig. 10, 


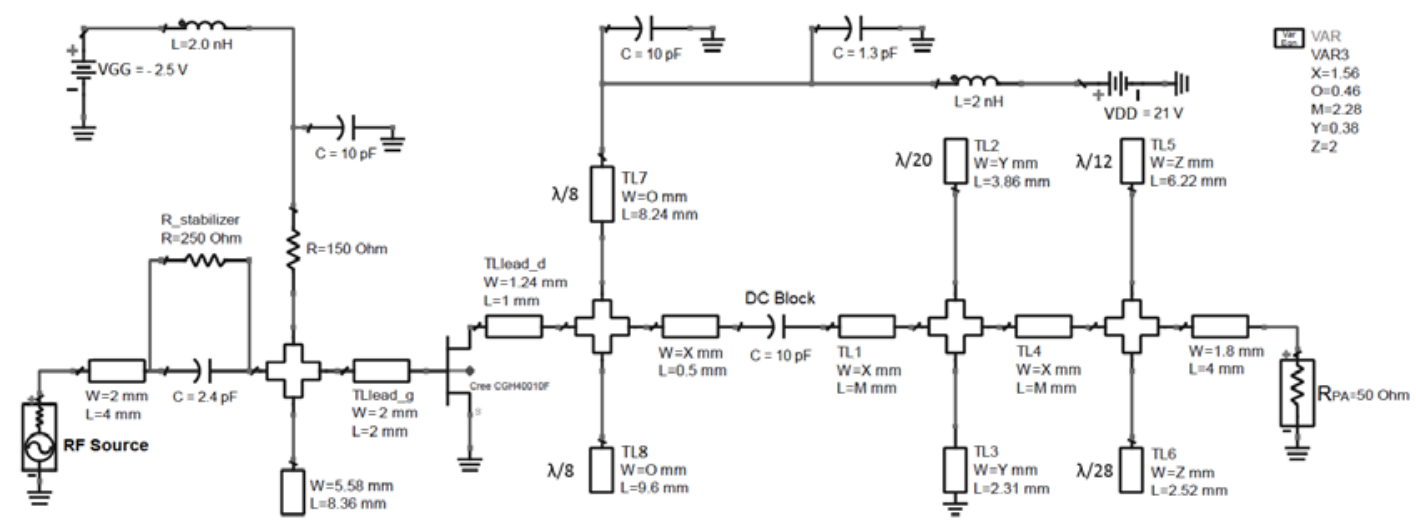

Fig. 4. Complete circuit schematic of the load-pull FHP Class-EF PA.

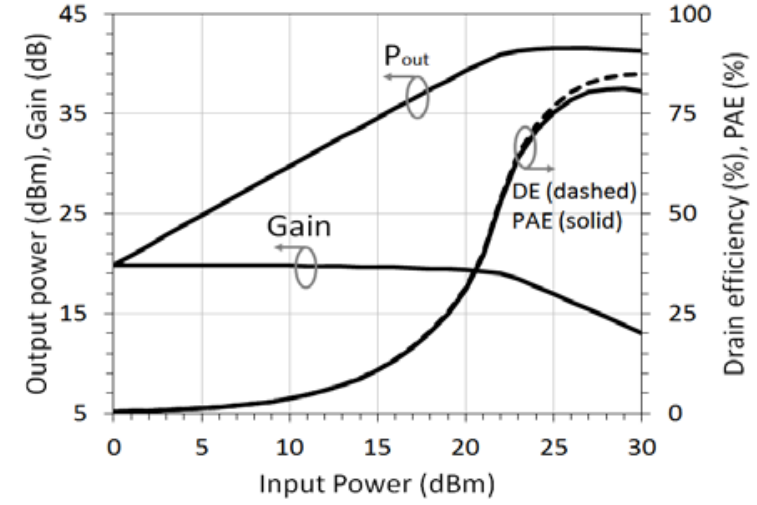

Fig. 5. Simulated output power, gain, $\mathrm{DE}$ and $\mathrm{PAE}$ versus input power of the load-pull FHP Class-EF PA $\left(f_{0}=2.4 \mathrm{GHz}\right.$ and $\left.V_{G G}=-2.5 \mathrm{~V}\right)$.

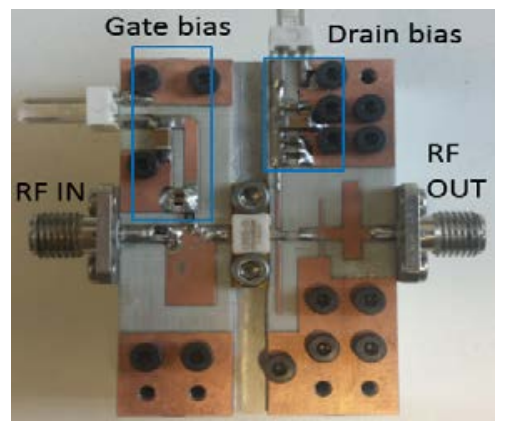

Fig. 6. The fabricated load-pull FHP Class-EF PA.

leading to a higher average efficiency (defined as a product of instantaneous efficiency and probability density function, e.g., Gaussian, Rayleigh, etc.). When the input drive voltage $v_{\text {in }}$ is reduced from $v_{\max }$ to $v_{\max } / 2$, the impedances that the Main and Auxiliary PA cells present to the output combiner are modulated accordingly from $R_{P A}$ to $2 R_{P A}$ and from $R_{P A}$ to infinity, respectively. Through this active load modulation, high efficiency across the back-off region as illustrated in Fig. 10 is achieved. The output combiner of the proposed DPA is comprised of three quarter-wave transmission lines, one at the Main branch $\left(\mathrm{TL}_{\mathrm{A}}\right)$ and two at the Auxiliary branch $\left(\mathrm{TL}_{\mathrm{B}}\right.$ and $\mathrm{TL}_{\mathrm{C}}$ ). A $90^{\circ}$ hybrid coupler is required to evenly split the input power and provide a $90^{\circ}$ phase shift at the input of the Main PA cell in order to compensate for the $90^{\circ}$ phase difference between the Main and Auxiliary paths. For a given $R_{P A}=$ $50 \Omega$ and standard load $R_{L}=50 \Omega$, the output-combiner transmission-line parameters can be calculated using the formulae given in Table II [13].

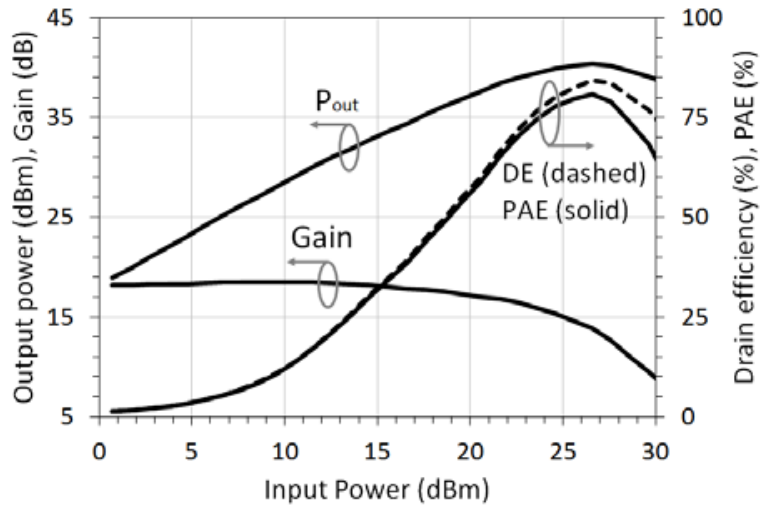

Fig. 7. Measured output power, gain, $\mathrm{DE}$ and $\mathrm{PAE}$ versus input power of the load-pull FHP Class-EF PA $\left(f_{0}=2.4 \mathrm{GHz}\right.$ and $\left.V_{G G}=-2.5 \mathrm{~V}\right)$.

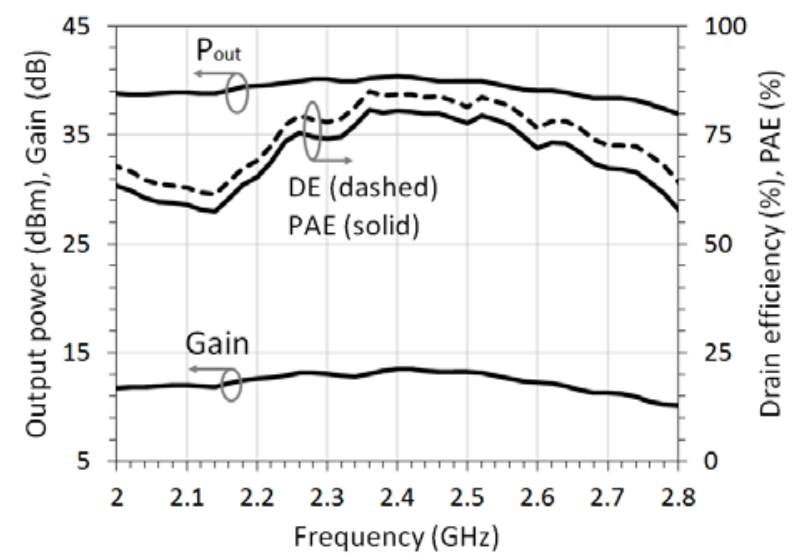

Fig. 8. Measured output power, gain, DE and PAE versus frequency of the load-pull FHP Class-EF PA $\left(P_{i n}=27 \mathrm{dBm}\right.$ and $\left.V_{G G}=-2.5 \mathrm{~V}\right)$.

At peak power i.e. when the input drive voltage $v_{\text {in }}=v_{\text {max }}$, both Main and Auxiliary PAs are ON, presenting a load impedance of $R_{P A}$ to the output combiner. The transmission line $\mathrm{TL}_{\mathrm{A}}$ transforms the Main PA's impedance $R_{P A}$ to $R_{P A} / \alpha^{2}$ $=2 R_{P A}$. On the other hand, the transmission line TLB transforms the Auxiliary PA's impedance $R_{P A}$ to $R_{P A} / \alpha=$ $\sqrt{2} R_{P A}$ which is subsequently transformed by TLC to $R_{P A} / \alpha^{2}=$ $2 R_{P A}$. Since $R_{P A}=R_{L}$, the two parallel $2 R_{P A}$ will provide a perfect match to $R_{L}$. At 6-dB BOP i.e. when the input drive voltage $v_{\text {in }}=v_{\max } / 2$, the Main PA is $\mathrm{ON}$, presenting a load impedance of $2 R_{P A}$ to the output combiner, whereas the Auxiliary PA is OFF, presenting an infinity load impedance to the output combiner. The transmission line $\mathrm{TL}_{\mathrm{A}}$ transforms the Main PA's impedance $2 R_{P A}$ to $R_{P A} /\left(2 \alpha^{2}\right)=R_{P A}$ which is matched to $R_{L}$. 


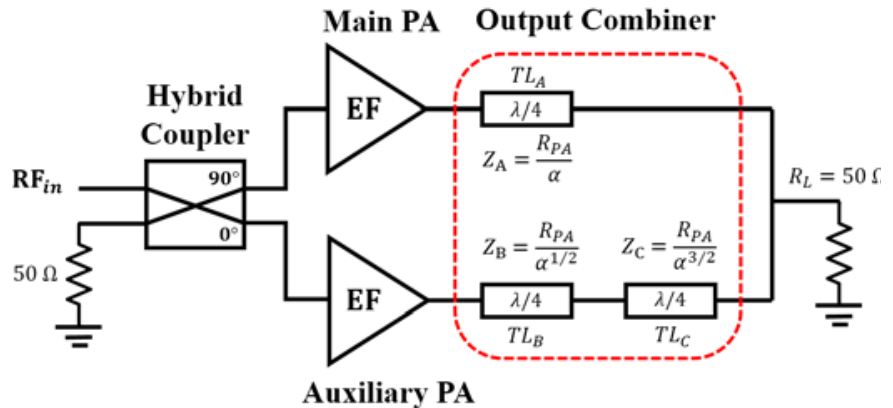

Fig. 9. Class-EF DPA block diagram.

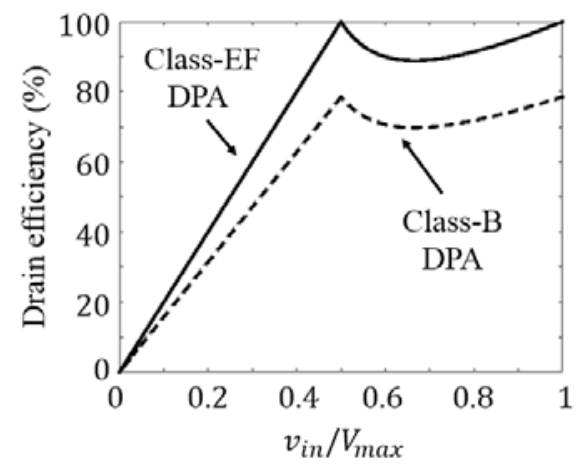

Fig. 10. Idealized drain efficiency versus normalized input voltage for Class-B and Class-EF DPAs.

TABLE II

OUTPUT COMBINER PARAMETERS

\begin{tabular}{ccc}
\hline \hline Parameter & Equivalent to & Value \\
\hline \hline $\boldsymbol{\alpha}$ & $\sqrt{R_{P A} /\left(2 R_{L}\right)}$ & 0.707 \\
\hline $\boldsymbol{Z}_{\boldsymbol{A}}$ & $R_{P A} / \alpha$ & $70.7 \Omega$ \\
\hline $\boldsymbol{Z}_{\boldsymbol{B}}$ & $R_{P A} / \sqrt{\alpha}$ & $59.5 \Omega$ \\
\hline $\boldsymbol{Z}_{\boldsymbol{C}}$ & $R_{P A} / \alpha^{3 / 2}$ & $84.1 \Omega$ \\
\hline \hline
\end{tabular}

The DPA circuit was realized on Rogers RO4003C substrate (Fig. 11). It employed two 10-W CGH40010F GaN HEMTs with drain and gate bias voltages optimized for best efficiency, resulting in $V_{D D}=28 \mathrm{~V}, V_{G G_{M A I N}}=-2.7 \mathrm{~V}$ and $V_{G G_{A U X}}=$ $-11.5 \mathrm{~V}$. A driver was connected to the input of the DPA to extend the input power range up to $37 \mathrm{dBm}$. Measurements using CW signal were performed with input power swept at $2.4 \mathrm{GHz}$. As shown in Fig. 12, the DPA exhibits a maximum $\mathrm{DE}$ of $81.3 \%$ at an output power of $45.3 \mathrm{dBm}$ and a $3.1-\mathrm{dB}$ compressed gain of $9.3 \mathrm{~dB}$. Drain efficiencies of $82.8 \%$ and $68 \%$ were recorded at 4 and $6 \mathrm{~dB}$ output BOP, respectively. Here, a 6-dB input BOP corresponds only to 4-dB output BOP due to the compression of the Main PA. Also shown in Fig. 12 is the DPA performance when $V_{G G_{A U X}}$ was increased to $-9.5 \mathrm{~V}$ while other bias voltages remained as before. Here, the transducer gain decreased to $11.8 \mathrm{~dB}$ from $12.4 \mathrm{~dB}$, and a maximum DE of $78.9 \%$ occurred at $45.2-\mathrm{dBm}$ peak power at which point the gain was compressed by $2.6 \mathrm{~dB}$.

The frequency behavior of the DPA at both peak power and 6$\mathrm{dB}$ output BOP levels is shown in Fig. 13. At peak power level, a maximum DE of $87.4 \%$ was obtained at $2.52 \mathrm{GHz}$, and the DE was maintained above $68.5 \%$ across the $2.3-2.6 \mathrm{GHz}$ frequency range. At 6-dB BOP level, a maximum DE of $71 \%$ was achieved at $2.38 \mathrm{GHz}$. The DE was maintained above $40 \%$

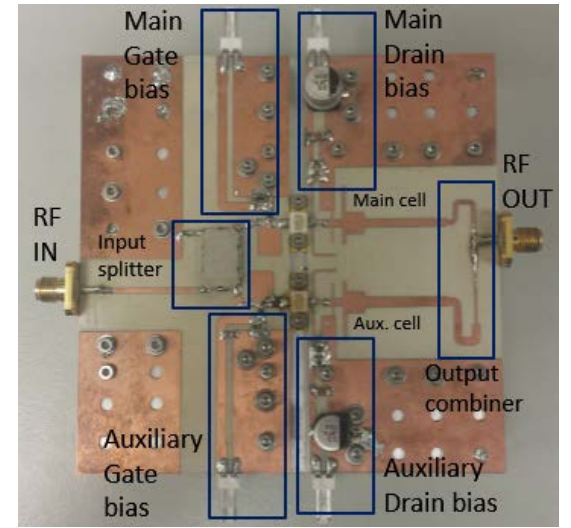

Fig. 11. The fabricated Class-EF DPA prototype $(10 \mathrm{~cm} \times 10 \mathrm{~cm})$.

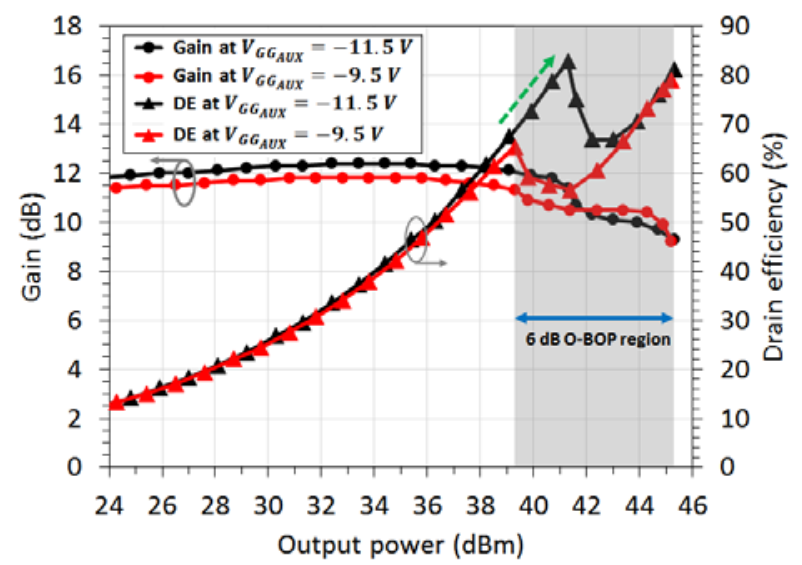

Fig. 12 Measured gain and DE versus output power of the Class-EF DPA $\left(f_{0}=2.4 \mathrm{GHz}, V_{D D}=28 \mathrm{~V}\right.$, and $\left.V_{G G M A I N}=-2.7 \mathrm{~V}\right)$.

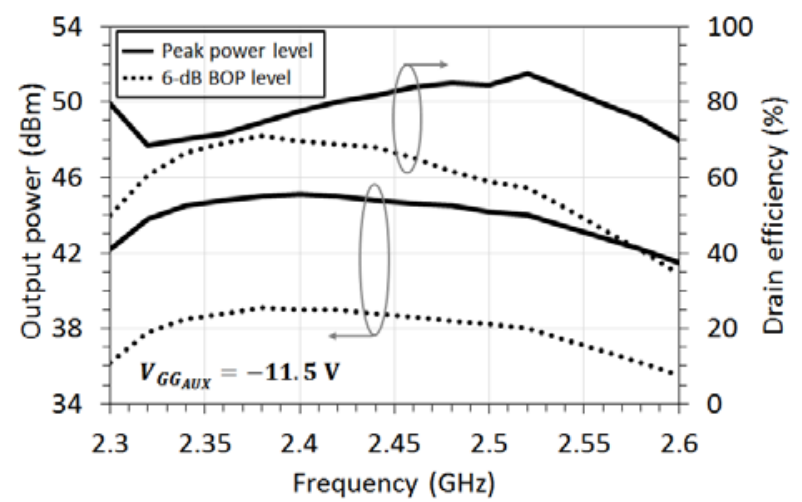

Fig. 13. Measured output power and DE versus frequency at both peak power and 6-dB output BOP of the Class-EF DPA.

within 280-MHz frequency range, i.e., from 2.3 to $2.58 \mathrm{GHz}$.

To examine the performance of the DPA with modulated signals, the DPA was excited by two modulated signals that were individually generated from Rohde \& Schwarz SMU200A signal generator, centered at $2.4 \mathrm{GHz}$, and analyzed by Rohde \& Schwarz FSQ40 spectrum analyzer. The first signal is a single carrier wideband code division multiple access (W-CDMA) 3GPP signal with $45^{\circ}$-quadrature phase shift keying (QPSK) modulation scheme, 5-MHz bandwidth, and 4.8-dB peak-to-average power ratio (PAPR). Whereas the second signal is a 16-state quadrature amplitude modulated (16-QAM) signal with 5-MHz bandwidth and 6-dB PAPR.

Figs. 14 and 15 show the measured adjacent channel leakage ratios (ACLRs) and DE using the aforementioned modulated signals. With the W-CDMA signal, a maximum DE of $73.4 \%$ 


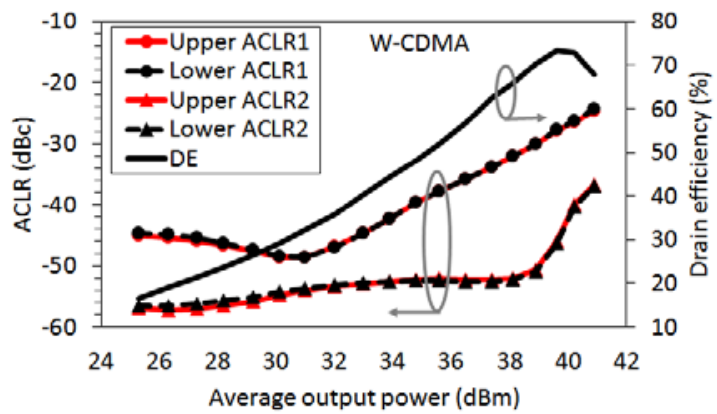

Fig. 14. Measured DE and ACLRs against the average output power with single carrier W-CDMA signal. ACLR 1 and $\mathrm{ACLR}_{2}$ are at 5- and $10-\mathrm{MHz}$ offsets from the carrier frequency, respectively.

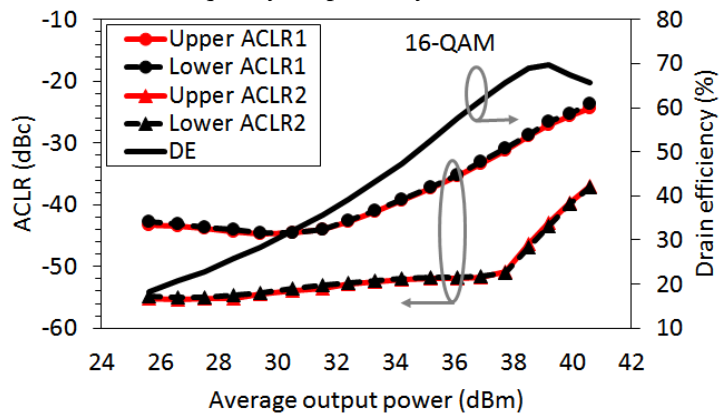

Fig. 15. Measured DE and ACLRs against the average output power with single carrier 16-QAM signal.

TABLE III

PERFORMANCE SUMMARY AND COMPARISON WITH OTHER PUBLISHED DOHERTY POWER AMPLIFIERS

\begin{tabular}{|c|c|c|c|c|c|}
\hline \multirow{2}{*}{ Ref. } & \multirow{2}{*}{ Class } & Freq. & \multirow{2}{*}{$\begin{array}{c}\text { PAAT } \\
\text { SAH })\end{array}$} & $(\mathrm{dBm})$ & \multicolumn{2}{|c|}{ Instantaneous DE (\%) } \\
\hline$[1]$ & $\mathrm{F}$ & 0.85 & 43 & Peak power & 6 -dB BOP \\
\hline$[2]$ & $\mathrm{F}$ & 2.14 & 35.1 & 54.7 & 58 \\
\hline$[3]$ & $\mathrm{E}$ & 2.14 & 46 & $72.5(\mathrm{PAE})$ & 61.2 \\
\hline$[4]$ & $\mathrm{F}^{-1}$ & 2.14 & 50 & 77 & $\mathrm{~N} / \mathrm{A}$ \\
\hline$[5]$ & $\mathrm{E}$ & 2.14 & 52.3 & 54 & 58.4 \\
\hline$[6]$ & $\mathrm{F}^{-1}$ & 2.6 & 57.3 & N/A & 53 \\
\hline$[7]$ & $\mathrm{J}$ & 2.7 & 45 & 79 & 60 \\
\hline$[8]$ & $\mathrm{F}$ & 3.5 & 46.8 & 64 & 53 \\
\hline$[14]$ & $\mathrm{AB}-\mathrm{C}$ & 2.14 & 44 & 68.2 & 51.5 \\
\hline$[15]$ & - & 0.85 & 48.8 & 64.7 & 63.8 \\
\hline$[16]$ & $\mathrm{AB}-\mathrm{C}$ & 1.8 & 40 & 45 & 28 \\
\hline This work & $\mathbf{E F}$ & $\mathbf{2 . 4}$ & $\mathbf{4 5 . 3}$ & $\mathbf{8 1 . 3}$ & $\mathbf{6 8}$ \\
\hline
\end{tabular}

with an $\mathrm{ACLR}_{1}$ of $-27.8 \mathrm{dBc}$ was achieved at an average output power of $39.6 \mathrm{dBm}$. Whereas using the 16-QAM signal the DPA exhibits a maximum DE of $69.7 \%$ with an ACLR $_{1}$ of $-26.6 \mathrm{dBc}$ at an average output power of $39.2 \mathrm{dBm}$. When comparing between the two signals we find that the DPA shows, at high power operation, lower DE values when using the 16-QAM signal due to its higher PAPR. To sum up, the modulated wave measurements have shown an exceptional efficiency with quite good linearity performance that could be enhanced using the familiar linearization techniques such as digital pre-distortion.

The performance of the DPA prototype is summarized in Table III, and when compared with other published DPAs the proposed Class-EF DPA offers superior drain efficiencies at both peak power and 6-dB BOP levels.

\section{CONCLUSION}

The Fifth-Harmonic-Peaking Class-EF PA has been, for the first time, employed as Main and Auxiliary cells of the Doherty
PA. The optimum fundamental-frequency load impedance of the FHP Class-EF cell was obtained using load-pull technique to give best PAE. The fabricated and tested PA cell delivered a peak output power of $40.4-\mathrm{dBm}$ at $84.4 \%$ DE. Continuouswave measurements of the DPA prototype at $2.4 \mathrm{GHz}$ have shown an excellent DE of $81.3 \%$ and $68 \%$ at peak power (45.3 $\mathrm{dBm})$ and 6-dB back-off power, respectively. The proposed DPA exhibits a 3-dB bandwidth close to $300 \mathrm{MHz}$ within which the DE is maintained above 68.5\%. Using modulated wave signals with 5-6 PAPR, the DPA exhibits ACLR 1 levels below $-26.5 \mathrm{dBc}$ with drain efficiencies higher than $69.5 \%$.

\section{ACKNOWLEDGMENT}

The authors wish to thank Kieran Rainey (QUB) for assistance in the circuit fabrication, and Bell Labs Nokia Ireland for providing access to the testing facilities.

\section{REFERENCES}

[1] M. N. A. Abadi, H. Golestaneh, H. Sarbishaei and S. Boumaiza, “An extended bandwidth Doherty power amplifier using a novel output combiner,” in IEEE MTT-S Int. Microw. Symp., 2014, pp. 1-4.

[2] P. Colantonio, F. Giannini, R. Giofre, and L. Piazzon, "Theory and experimental results of a class F AB-C Doherty power amplifier," IEEE Trans. Microw. Theory Tech., vol. 57, no. 8, pp. 1936-1947, Aug. 2009.

[3] Y.-S. Lee, M.-W. Lee, and Y.-H. Jeong, "High-efficiency Class-E-cellsbased GaN HEMT Doherty amplifier for WCDMA applications,” in Eur. Microw. Conf., 2008, pp. 428-431.

[4] A. Grebennikov, "A high-efficiency 100-W four-stage Doherty GaN HEMT power amplifier module for WCDMA systems,” in IEEE MTT-S Int. Microw. Symp. Dig., 2011, pp. 1-4.

[5] E. Takahashi, T. Ishikawa, K. Kashimura, and N. Adachi, "Highefficiency four-stage Class-E Doherty amplifier for W-CDMA base stations,” in Eur. Microw. Conf., 2008, pp. 234-237.

[6] H. Deguchi et al., “A 2.6 GHz band 537W peak power GaN HEMT asymmetric Doherty amplifier with $48 \%$ drain efficiency at 7dB,” in IEEE MTT-S Int. Microw. Symp. Dig., 2012, pp. 1-3.

[7] N. Tuffy and L. Pattison, "A linearized, high efficiency $2.7 \mathrm{GHz}$ wideband Doherty power amplifier with Class-J based performance enhancement," in Eur. Microw. Conf., 2015, pp. 215-218.

[8] C.-Z. Fan, X.-W. Zhu, J. Xia, and L. Zhang, "Efficiency enhanced ClassF Doherty power amplifier at $3.5 \mathrm{GHz}$ for LTE-Advanced application,” in Asia-Pacific Microw. Conf., 2013, pp. 707-709.

[9] A. Grebennikov, "High-efficiency Class-FE tuned power amplifiers," IEEE Trans. Circuits Syst. I, Reg. Papers, vol. 55, no. 10, pp. 32843292, Nov. 2008.

[10] M. Thian and V.F. Fusco, "Analysis and design of Class-E3F and transmission-line Class-E3F2 power amplifiers,” IEEE Trans. Circuits Syst. I, Reg. Papers, vol. 58, no. 5, pp. 902-912, May 2011.

[11] M. Thian, A. Barakat, and V. Fusco "High-efficiency harmonic-peaking Class-EF power amplifiers with enhanced maximum operating frequency,” IEEE Trans. Microw. Theory Techn., vol. 63, no. 2, pp. 659671, Feb. 2015.

[12] S. C. Cripps, RF Power Amplifiers for Wireless Communications. Norwood, MA, USA: Artech House, 2006.

[13] A. Barakat, M. Thian, and V. Fusco, "Towards generalized Doherty power amplifier design for wideband multimode operation," in SBMO/IEEE MTT-S Int. Microw. Optoelectronics Conf., 2015, pp. 1-5.

[14] R. Darraji and F. M. Ghannouchi, "RF/DSP codesign methodology of enhanced Doherty amplifiers," IEEE Trans. Circuits Syst. II, Exp. Briefs, vol. 59, no. 4, pp. 219-223, Apr. 2012.

[15] J. h. Kwon et al., "Broadband Doherty power amplifier based on asymmetric load matching networks,” IEEE Trans. Circuits Syst. II, Exp. Briefs, vol. 62, no. 6, pp. 533-537, Jun. 2015.

[16] S. Y. Zheng, Z. W. Liu, Y. M. Pan, Y. Wu, W. S. Chan and Y. Liu, "Bandpass filtering Doherty power amplifier with enhanced efficiency and wideband harmonic suppression,” IEEE Trans. Circuits Syst. I, Reg. Papers, vol. 63, no. 3, pp. 337-346, March 2016. 